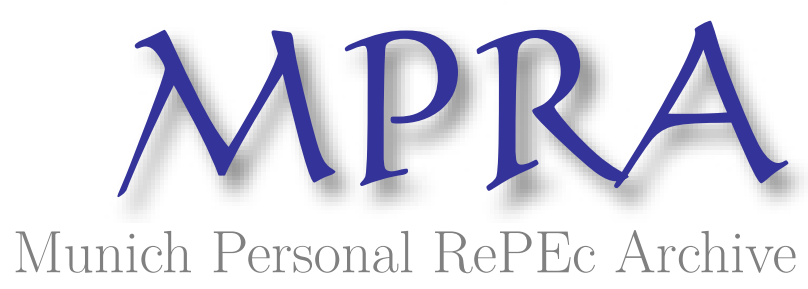

\title{
Unemployment Insurance Schemes, Liquidity Constraints and Re-employment: a three Country Comparison
}

Corsini, Lorenzo

University of Pisa

January 2012

Online at https://mpra.ub.uni-muenchen.de/36572/

MPRA Paper No. 36572, posted 11 Feb 2012 08:23 UTC 


\title{
Unemployment Insurance Schemes, Liquidity Constraints and Re-employment: a three Country Comparison
}

\author{
Lorenzo Corsini* \\ University of Pisa
}

\begin{abstract}
We examine how unemployment schemes and liquidity constraints affect reemployment probabilities and unemployment duration. In particular we investigate to which extent those schemes, through employment services and search requirements, can offset the expected perverse effect of benefits on reservation wages and search effort. Similarly, given that liquidity constraints and financial pressure should also affect reservation wage and search effort we analyze whether better economic conditions of individuals actually increase duration. We perform the analysis on Finland, Italy and Poland, countries that displays significant differences both in the UI schemes generosity and eligibility criteria and in the overall degree of social wealth and economic prosperity. Using a sample of newly unemployed from these countries, we perform and estimation of Cox hazard models and assess what variables are important in determining unemployment duration. Our findings suggest that even correctly designed UI schemes have a mixed effect: initially they give incentive to increase search effort, as the eligibility criteria impose certain search requirements, but with time they simply reduces liquidity constraints and thus increase duration. As for the direct effect of liquidity constraints and financial pressure we found that in Italy and Poland they appear to reduce unemployment duration but they are not relevant in Finland, suggesting that these aspects are not so important in countries that are particularly rich and with a developed welfare system.
\end{abstract}

Keywords: Unemployment Insurance, Liquidity constraints, Re-employment, Unemployment Duration

\footnotetext{
* Lorenzo Corsini, Department of Economics, University of Pisa, Via C. Ridolfi, 10, 56124 Pisa, Italy. Tel: +39 0502216220; E-mail: lcorsini@ec.unipi.it. The author would like to thank for their useful comments the participants of the International Workshop "Crises, Institutions and Labour Market Performance: Comparing Evidence and Policies Market Failures and the Role of Institutions" held in Perugia, Italy in November 2011. Suggestions from Giuseppe Croce were particularly useful. The analysis is based on data obtained from European Commission, Eurostat, longitudinal EU-SILC/2011/08. Eurostat has no responsibility for the results and conclusions which are those of the researcher. The usual disclaimer applies.
} 


\section{The unemployment insurance schemes in Finland, Italy and Poland}

Unemployment insurance (UI) schemes represent a well-established institution that aims to support individuals during unemployment spells. These schemes are present in all OECD countries and though the exact mechanisms and regulation differ from country to country, the backbone of the schemes is almost the same everywhere: the UI schemes provide periodic payments to unemployment individuals for a (usually) limited amount of time, subject to some eligibility criteria that workers have to meet. While helpful in mitigating the adverse condition that unemployed workers may face, economics theory (and job search theory in particular) has stressed that unemployment benefits may affect for the worse re-employment probabilities. In fact, payments given to unemployment individuals raise their reservation wages and decrease the cost of being unemployed, reducing search effort; thus, UI should increase unemployment duration.

However, things are more complicated than this simple depiction and, as they stressed in their popular survey on this subject, Atkinson and Micklewright (1991) argue how the actual mechanism that is governing the implementation of benefits is certainly relevant in establishing the exact link between benefits and unemployment duration. As a matter of fact, actual UI schemes include some eligibility criteria and some of these criteria imply the requirement for worker to prove of being actively searching and to devise a plan (together with employment centers (EC) or similar institutions) on which steps to take to search more effectively. The existence of further incentives to search actively and the support and counseling obtained from EC may outweigh the perverse consequences and thus, UI schemes could, in principle, reduce unemployment duration. Even from an empirical point of view the actual effect of benefits on duration is not so clean cut ${ }^{1}$ : Atkinson and Micklewright (1991) review a large number of empirical studies and conclude that the evidence is mixed and, all things considered, benefits seem to affect positively duration but their effect is, at most, feeble.

Another relevant aspect that should be considered when investigating the determinants of unemployment duration is related to liquidity constraints. The liquidity constraints of individuals largely affect both reservation wages and search effort and, through them, unemployment duration. Thus, it is possible that unemployed individuals belonging to households of different wealth (and

\footnotetext{
${ }^{1}$ There is a large number of studies on the effect of UI schemes, though these analysis are seldom carried out from a comparative perspective. A good review of the first empirical studies on the effect of unemployment benefits is contained in the aforementioned Atkinson and Micklewright (1991) where they clearly indicate duration models as the main tool to estimate the effect of unemployment benefits. A group of relatively more recent studies focus on the role of eligibility criteria on the search effort and unemployment duration. These studies are based on field experiments and perform causality analysis distinguishing between treated/non treated groups, trying to assess whether the criteria imposed to be eligible for benefits affect or not search behaviour. The results of the conclusion of these studies are mixed: Klepinger et al (2002) performs a causality analysis using the data Maryland UI work-search demonstration (a plan that randomly assigned benefits recipients to different search criteria) and show that stricter criteria improved search efforts and reduced unemployment duration. Somehow differently, Ashenfelter et al. (2005) exploit differences in the eligibility criteria of different American states (Connecticut, Massachusetts, Virginia and Tennessee) to conduct an experiment and finds out that stricter search criteria do not affect sensibly the access to benefits. Manning (2009) uses a difference in differences estimations to capture the treatment effect on unemployment duration, using the change of unemployment benefits regulation that happened in UK in 1996: his results indicates that criteria affect the access to claims but stricter criteria discourage workers to effectively meet the search requirement and thus do not facilitate the transition to an employment. Several works have also tried to assess the role of unemployment benefits maximum duration on unemployment duration: Nickell and Layard (1999) gives an assessment of this issue and suggest that benefits duration and unemployment duration are positively correlated..
} 
under different financial stress) may exhibit differences in terms of search effort and of reservation wage and, eventually, in the probability of leaving unemployment. More in particular, we can imagine that wealth and the degree of financial stress of individuals determine liquidity constraints and affect duration. Basically, unemployed workers living in richer households and with less financial stress are likely to feel less pressure to search for a job or to accept any offer they might receive: thus, all things being equal, wealthier unemployed should experience longer duration. This latter aspect has received some attention but has not been fully assessed nor has been analyzed in a comparative perspective. An interesting analysis is contained in Bloemen (2002) where a proxy variable for wealth is computed and its effect on the probability of obtaining a job is tested. However the analysis does not focus on unemployment duration. Chetty (2005 and 2008, with the latter being an extend version of the former): in them the author tries to use evidence from US to disentangle the moral hazard and liquidity constraint effects that benefits have on unemployed workers. This is obtained using cox hazard models to perform estimations for different groups of people, defined by their being liquidity constrained or not. In addition estimations using data on lump sum severance payment only are also performed: since no moral hazard behaviour can derive from these kinds of payments this procedure allows to focus only on the role of liquidity constraints; the results indicate that the liquidity constraint motive seems to be more relevant than the moral hazard one. On a similar topic Card, Chetty and Weber (2007) use a regression discontinuity approach on Austrian data and try to evaluate the effect of a lump sum benefits and of maximal potential duration of benefits on the search behaviour and unemployment duration, where the discontinuity stems from the eligibility criteria for the unemployment benefit scheme in Austria. Since the effect of severance payment and of maximum duration appears to be similar, they conclude that liquidity constraints motives seems to be more relevant than moral hazard one (which should be absent in the case of the extensions of the severance payment).

Our paper contributes to these analyses on the determinants of unemployment duration and it focuses both on the effect of UI schemes and on the role of liquidity constraints. In particular we take a comparative approach, analyzing different countries, something that has hardly been done before. The comparative dimension is particular useful within this context: on the one hand, it allows us to exploit institutional differences in the mechanisms regulating the UI schemes to better assess the exact relationship between UI and duration; on the other hand it allows to assess which schemes are more effective (or less perverse) in terms of unemployment duration. In the present work we analyze three different countries: Finland, Italy and Poland. These countries allow us to analyze a wide spectrum of economic systems and UI schemes characteristics. Finland is an advanced country with a strong welfare system: its UI scheme is generous and long in duration; it provides support in the job search process and imposes (and effectively supervises) active search from individuals. On the other hand, Poland is a former transition economy which is still facing some economic problems, unemployment being probably the most relevant: its UI scheme is not particularly generous and it offers only minor employment services nor it includes any job search requirements. Italy is somehow midway, being an advanced countries with problems of growth and with relevant regional disparities: its UI scheme is among the least generous and while in principle the law establishes both employment services and active search requirements, the actual and specific implementation is left to the local employment services so that the effectiveness of these measures vary considerably. 
Our investigation uses data on employment status, income and wealth of individuals for the year 2007 from the EU-SILC survey. The data allows to determine the exact unemployment duration and the payments received from UI schemes. We focus only on workers that have just became unemployed so that the duration of unemployment before the period of observation is the same (being equal to zero) for all individuals: this allows to have a more homogenous group of observations and to get rid of any possible left censoring problem. We develop a survival analysis (where the non-survival condition consists in finding a job) and we use Cox hazard models to estimate the determinants of duration of unemployment, paying particularly attention to the role of unemployment benefits (both at the start of the scheme and during the duration of the unemployment spell) and of the degree of liquidity constraints. We use three main variables to assess the degree of liquidity constraints: the payment of interests for mortgage, the amount of taxes on wealth (which is a proxy for actual wealth) and the self-assessed degree of economic problems (that, in the database, is obtained from the answer to the question "all things considered, is the household able to make ends meet?"). We allow for the effect of benefits and of the financial variables to be different across the three countries, so that we are able to assess how the different UI schemes affect the unemployment duration as well as differences in the role of liquidity constraints.

The results we obtain are interesting both with regards to the effect of unemployment benefits and to the role of liquidity constraints. In particular, while the more developed and search supportive schemes of Finland and, partially, of Italy seem to initially have a positive effect on reemployment probabilities, they turn out to affect negatively those probabilities as time passes. Apparently, the initial boost to the effort and to the quality of the job search wears out and the standard effect of benefits on reservation wage and search effort takes over. This is true even for Finland where a strict control of employment services and search activity is maintained through all the duration of the benefits. The Polish scheme on the contrary does not affect duration, neither positively or negatively. The results on the degree of liquidity constraints are also interesting: the financial conditions and the degree of financial stress of individuals are particularly relevant for Italy but not for Finland, probably indicating that individual financial conditions are less relevant in countries whose economy is faring well and with an extensive welfare system. Results for Poland are instead mixed as only some dimensions of financial stress reduce duration.

The works is organized as follows: in section two we present the UI schemes for the three countries, in section three we describe the data and we highlight some descriptive differences between the countries, in section four we perform our empirical analysis and discuss possible interpretations of our results and in section five we conclude.

\section{The unemployment insurance schemes in Finland, Italy and Poland}

We describe here the unemployment insurance (UI) schemes of the three countries related to 2007. Table 1 contains a summary of the main characteristics of the schemes as well as an overall assessment of their generosity in terms of the OECD ranking of the generosity of the scheme (in 2007) as reported in the OECD Employment Outlook 2009.

\section{TABLE 1}


Finland has a two-tier scheme. The first tier is a voluntary UI that workers can subscribe. The benefits are payable to any registered unemployed person, who is between 17 and 64 years old, who is available for and actively seeking full-time work. The eligibility criteria require 43 weeks of work in the last 28 months and the payment of at least 10 months of voluntary contribution before the claim. Workers receive a basic benefit of $17 \%$ of the average national wage (11.50 euro per week in 2007) plus up to $45 \%$ of past earnings exceeding the basic benefit. Maximum duration is 100 weeks but older workers can qualify for extensions. The second tier is a defined as labour market support: it is payable to any registered unemployed person, who is between 17 and 67 years old and is available for and actively seeking full-time work; there are no pre-employment conditions to receive it. The actual amount is given by the basic benefit (17\% of the average wage) reduced according to the household income; the benefit for younger workers living with their parents is reduced even further. The duration of this support is unlimited. The overall ranking in generosity of the Finnish scheme among the OECD countries is 9th out of 29, making it a quite generous scheme and, in particular, it displays a much longer duration than average. It should also be noted that Finland welfare system allows for another social assistance benefit that acts as a safety net and that is given solely on the base of income and independently of employment (and searching) status.

The Italian UI scheme entitles unemployed individuals to receive ordinary unemployment benefits under the following conditions: to not have voluntarily left the last job; to have hold a job during the last 2 years, to have paid compulsory contributions to social security for at least 52 weeks during the last two years and to have declared to the local employment center the wiliness to work and to have agreed with the employment center a specific program to search for jobs. The benefit amounts to $50 \%$ of the average wage computed during the three months before losing the last job. Standard maximum duration is 6 months but workers receive lower benefits (40\% of wage) during the 7 th. Workers whose age is above 50 receive benefits also after the 7 th month for a total maximum of 10 months (but during the tenth month the benefits is $30 \%$ of wage). The overall ranking in generosity of the Italian scheme is $27 \mathrm{th}$, placing it almost at the bottom of the ranking and being particularly lacking in term of maximum duration.

Apart from basic UI, two other Italian institutions are worth to mention: Cassa Integrazione Guadagni (CIG) and mobility unemployment benefit. The CIG is given to temporary laid off workers (or working reduced hours) and is given in the case of unfavorable economic conditions following an agreement between firms and the government. Individuals on this scheme receive $80 \%$ of gross wage for the work time lost. It is important to stress that workers under the CIG scheme retain their job contract (their contract is not terminated) and are not classified as unemployed: thus, even if they receive a form of income support, they do not actually enter our analysis. Mobility unemployment benefits are given to workers previously on CIG benefits whose firms have proceeded in collective dismissals or have gone bankrupt. In the former case, whenever the firm that has laid-off the worker hires a new employee, it is forced to offer the job first to workers currently on mobility unemployment benefits. It follows that these workers are slightly more likely to find a new job. The duration of these benefits is particularly long (from 12 to 48 months, depending on the sector and the geographical area) and they receive $80 \%$ of their gross wage. In any case there are actually very few individuals receiving this kind of benefits, (only $3 \%$ according to the Bank of Italy survey on household income and wealth). 
The Polish UI scheme grants benefits to registered unemployed individuals that are able and ready to take up employment. The contribution to the scheme is compulsory and workers are entitled to receive the benefits if, during the period of 18 months preceding the day of registration as unemployed, they have been employed for at least 365 days and if the termination of the contract was not voluntary. The benefit amounts to $24 \%$ of the average national wage (that is, about 151 euro per month in 2007) but it is adjusted according to the length of past employment spells (so that more experienced workers receive higher benefits). Maximum duration is 6 months but it is increased to 12 or 18 for individuals from areas where unemployment rate is higher than national average. The overall ranking in generosity of the Polish scheme among the OECD countries is 21th out of 29, making it lower than average in terms of generosity. It should also be noted that Polish welfare system allows for another social assistance benefit that acts as a safety net and is given solely on the base of income and independently of employment status.

This far we have described the UI schemes in terms of eligibility criteria, benefits amount and maximum duration. However, together with actual income support, the UI schemes may also provide some form of employment counseling and require active job search activities. In particular, the schemes usually provide some employment services (ES) and counseling through the local employment centers and might requires some proofs of active search. We summarize in table 2 the main forms of services and search requirement in the three countries: a detailed description of these aspects can be found in the OECD Employment Outlook 2007.

\section{TABLE 2}

The Finnish scheme requires that, at the moment of registration, the EC have to check for suitable vacancies and offer them to unemployed workers. On the other side, workers have to apply for the offered vacancies. In addition, the EC and the unemployed have to agree on an individual action plan (IAP) describing specific action to search more effectively for jobs. After this initial stage, workers have to report monthly to a counselor providing also proof of actual search efforts.

The Italian laws on UI scheme prescribe that local EC have to devise together with the worker an IAP describing specific actions that workers have to follow and how to check search progress. In this sense, Italian law do not prescribe compulsory placement efforts from ES nor describe exactly if and how workers' search activity should be checked; however, these aspects may become compulsory depending on the local EC programs.

The Polish scheme requires that at the moment of registration, employment center have to check for suitable vacancies and offer them to the unemployed workers. Accordingly, workers have to apply for the offered vacancies. No IAP is expected to be carried out nor there is a search requirement to be fulfilled during the employment spell, though individuals have to report monthly by post whether they are still unemployed.

Summing up, we observe that the three countries offer different degree of counseling and requirements in terms of search: on one side there is Finland that offers accurate employment service and requires strict controls of search effort; on the other there is Poland where employment services are barely present and where search activity is not required. Somewhere between falls Italy, whose legislation in principle prescribes that employment services should be offered and that 
workers should search actively to be eligible for benefits; however, the actual implementation of these principles is left to the local EC so that large differences may exist from area to area.

\section{Data description}

We use data from the EU-SILC 2008 survey, which contains detailed data on individuals and households in 2007. The survey allows us to identify newly unemployed individuals and we perform our analysis on them. We define as newly unemployed an individual that is currently unemployed and that, in the previous months, was in paid employment or self-employed. The survey contains the working status for each calendar month and therefore we are able to identify newly unemployed and to compute unemployment duration in months for those individuals that end up finding a job. According to EU-SILC survey classification we consider unemployed an individual that has specifically declared unemployment to be his status and has declared not to be currently in paid work, in self-employment nor to fall in the following categories: retired, student, military activity or other inactivity. According to EU-SILC classification, individuals on temporary lay-off are considered employed if they receive at least $50 \%$ of their gross wage, thus we do not consider workers on the Italian CIG scheme as unemployed. In the computation of unemployment duration we also include workers that were still unemployed during December 2007, but their condition results censored as we do not know when and if they eventually find a job. We end up with a sample of 195 newly unemployed workers for Finland, 536 for Italy and 471 for Poland. The survey contains information about the demographic characteristics (age, gender, marital status, education, region of dwelling and so on) and on the economic characteristics both of the individual and of the household (basically, income from unemployment benefits and some measures of the household wealth). The information on income from unemployment benefits takes the form of the total income from ordinary unemployment benefits, mobility benefits and severance payments: we divide this amount for the total months of unemployment in 2007 to obtain the average monthly benefits.

The EU-SILC survey also contains some data on household wealth and financial conditions that we use in our analysis. In particular, we use the amount of taxes on wealth per household equivalised component ${ }^{2}$ as a proxy for household wealth. We also use the amount of interests on the mortgage (if any) paid yearly and, finally, we use some qualitative information on the household economic situation that in the survey takes the form of a question on whether the household was able to make ends meet ${ }^{3}$ to which the individuals could give six different answers: "with great difficulty", "with difficulty", "with some difficulty", "fairly easily", "easily" and "very easily".

It is interesting to give a description of how some key variables vary across the three countries. In figure 1a we represent the share of newly unemployed that found a job within the year 2007: as it is clear from the figure, the share is fairly large in Finland and somehow in Italy, but is significantly smaller in Poland. Similarly, the share of newly unemployed that received benefits (see Figure 1a) is large in Finland and quite large in Italy, whereas benefits are much less frequent in Poland.

\footnotetext{
${ }^{2}$ The equivalence scale takes into account the age component. A full description of the scale can be found in Eurostat (2007).

${ }^{3}$ The exact form of the question in the EU-SILC questionnaire was: "Concerning your household's total monthly or weekly income, with which degree of ease or difficulty is the household able to make ends meet?"
} 


\section{FIGURE 1}

A depiction of the wealth and financial condition is given in figure 2. Mortgages (figure 2a) are relatively frequent in Finland whereas they are not so common in Italy and hardly present in Poland. ${ }^{4}$ What is really interesting is the distribution of unemployed workers in terms of wealth (figure 2b): in Finland about 23\% belong to the top quartile of the wealth distribution (considering all the households in the population) implying that unemployment is spread almost evenly among households of all wealth classes. On the contrary, and probably more in line with what one should expect, unemployed individuals in Italy and Poland are less likely to belong to wealthier family. On similarly lines, unemployment in Finland does not appear to affect too much the self-perception of the degree of economic problems (figure 2c), as only $10 \%$ of unemployed individuals come from households with major economic problems. This is not true for Italy and in particularly for Poland, where unemployed workers come from households that often declare to have major problems. The overall impression from this data is that in Finland being unemployed is more common and less traumatic than in the other two countries: in fact, Finnish unemployed workers are spread quite evenly among all wealth classes and they do not often report major economic problems.

\section{FIGURE 2}

\section{Empirical Analysis}

In this part we perform an econometrical analysis of the unemployment duration: we focus in particular on the effect that unemployment benefits, wealth and financial pressure have on duration. Our total sample is made of 1202 individuals that during the year 2007 became unemployed. We perform a survival analysis, that is, we aim at estimating the probability that an unemployed finds a job and how this probability is affected by the passing of time and by some selected covariates. Basically, we assume the existence of a function $h(t)$ that determines the probability that individuals move from unemployment to employment at time $t$, conditional to the fact that the individual is still unemployed at time $t$ : this is called the hazard function. If we define as $F(t)$ the probability of not being unemployed after $t$ periods, with $S(t)=1-F(t)$ (that is, $S(t)$ is the probability of still being unemployed after $t$ periods, also known as survival function) and with $f(t)=F^{\prime}(t)$ (that is, $f(t)$ is the probability to switch from employed to unemployed at exactly time $t$ ) we have:

1) $h(t)=f(t) / S(t)$.

To perform our estimation we assume that $f(t)$ takes the form of a specific distribution and that it thus depends on a set of parameters $\theta$ describing the distribution and on a set of covariates $x$ that influence the probability of leaving unemployment: given a certain $f(t)$ it is possible to determine $h(t)$ and we can write the hazard function as $h(t, \theta, x)$ where $\theta$ are the actual parameter to be estimated. We also assume that the effect of the covariate is the same in each period, an assumption that gives the Proportional Hazard Model which can be written as:

$$
h(t)=h_{0}\left(t, \theta_{0}\right) \cdot \rho\left(x, \theta_{x}\right)
$$

\footnotetext{
${ }^{4}$ The extreme scarcity of mortgages in Poland is not a peculiarity of unemployed individuals: a similar frequency is also found in the population as a whole.
} 
where $h_{o}\left(t, \theta_{o}\right)$ is known as the baseline hazard function, which is the same for all individuals and only depends on time (and parameters) and where $\rho\left(x, \theta_{x}\right)$ determines the effects of the covariates (which are independent of time $t$ ). In our econometrical analysis we estimate equation 2 through Cox estimation and we obtain estimations of the parameters $\theta_{x}$ and this allows us to determine which variables are relevant in explaining duration. At first we perform a parametric Cox regression assuming that a Weibul distributed hazard function and we then perform a semi-parametric analysis (that is, without making any assumptions on the exact function form $h_{o}\left(t, \theta_{0}\right)$ ) to check for robustness. Given that we are dealing with observations coming from different countries we adopt a stratified approach and assume the baseline hazard functions to be country specific so that we estimate an ancillary parameter (the parameter that defines the shape of the hazard function) that is different for each country. In addition, since we are particularly interested in the role of the UI schemes and of liquidity constraints we allow for the variables measuring benefits and the financial conditions to have country specific coefficients. Therefore we estimate the following

3) $h(t, j)=h_{0, j}\left(t, \theta_{0}\right) \cdot \rho\left(x, \theta_{x}, y, \theta_{y, j}\right)$

where $j$ determines the country of origin and $y$ are the variables whose coefficients are country specific (benefits and the financial condition variables).

We start our analysis presenting the hazard estimates (figure 3) for the three countries: basically, these are descriptive measures of the probability of finding a job conditional to have spent a given amount of time in unemployment.

\section{FIGURE 3}

The patterns represented in figure 3 shows that the conditional probability has similar patterns but different scales in the three countries. In particular, the conditional probability at first slightly increases (in particular in Poland), then is stable for a while and finally declines. This homogeneity of behaviour changes if we examine the conditional probability of finding a job for individuals with and without unemployment benefits (figure 4).

\section{FIGURE 4}

The patterns in figure 4 are quite striking: in Finland and Italy workers on unemployment benefits have initially higher re-employment probabilities but this relationship reverts through time. The contrary is true for Poland, where individuals on benefits have lower probability at start but they end up with higher chances.

These finding, though extremely interesting, create a problem in the actual estimation of Cox proportional hazard model. In fact, one of the key assumption of this model is that the effect of a given covariate is the same through time (that is, the two patterns in figure 4 should be more or less parallel within each country) and figure 4 seems to indicate a violation of this assumption. To overcome this problem ${ }^{5}$ we add another variable which is given by the interaction (product) of

\footnotetext{
${ }^{5}$ We also performed the test for proportionality assumption proposed by Grambsch and Therneau (1994) on the residuals from an estimation of the Cox hazard model: the test refused the assumption of proportionality related to (and only to) the unemployment benefits.
} 
unemployment benefits and time: this takes into account the time-varying effect of benefits and solves the problem of non-proportionality.

The key variables we use in our estimation are the amount of benefits, the interaction of benefits with time and the three variables that give account of household wealth and financial conditions: 1 ) the amount paid for the mortgage, 2) taxes paid on wealth (divided by the equivalised size of households) and 3) a qualitative variable that represents, according to the individuals, whether the household is "having problems in making ends meet". This latter variable takes the form of a dummy which is one if the household experiences great difficulty or difficulty in making ends meets. Since we are particularly interested in comparing the effect of these variables among the different countries, we allow for country specific coefficients for the five key variables. Clearly, we also add several other control variables and in particularly we include age, gender, education and region of origin ${ }^{6}$. Finally, to account for unobserved heterogeneity we added a variable which measures months spent in unemployment in $2006^{7}$ and that should capture unobservable characteristics of the individuals that make them more likely to stay in unemployment. The use of this variable that takes into account unobservable also helps us to mitigate the effect of selfselection into benefits receipt. Table 3 presents the results for estimations of cox models: in the table, a positive coefficient tells implies a positive relationship with the probability of finding a job and thus a negative relationship with unemployment duration. Model (i) reports the estimation results from the parametric regression whereas model (ii) adopts a semi-parametric approach and we use the latter to check the robustness of our results.

\section{TABLE 3}

The results from model (i) on the effect of the UI schemes indicate two patterns depending on the country of origin: in Finland and in Italy being on the UI schemes produces a statistically significant effect on unemployment duration, but this effect change with time. At first, being registered for the UI implies a strictly higher probability of finding a job but this effect reverts with time. Apparently the employment counseling received at the moment of the registration of benefits exerts a positive effect on the quality and the quantity of search. However, after this initial effect, the boosts on the effort seem to dissipate and the standard effect of benefits on reservation wage and search effort takes place. It is important to stress that this is true even in Finland where the mechanism of employment counseling and the checks on active search takes place each month: apparently, even when these aspects are carried out efficiently, only the initial counseling exerts a relevant effect, whereas the following checks on effort are not able to be effective. The situation is different in Poland where employment services are carried out less extensively and in fact the UI does not display a significant improvement on re-employment probabilities; in any case, it is important to stress that even in Poland benefits do not reduce significantly the employment probabilities.

\footnotetext{
${ }^{6}$ In particular we use age and age squared to take into account non-linear effect of aging. Education enters the regression as a dummy which is one if individuals have at least upper secondary education (ISEC degree 3 or higher) and zero otherwise. The region of origin is expressed as a dummy which is one if individuals come from a region whose GDP is less than $75 \%$ of the country average. Different measures for education and place of origin were also tried, but these two were the most significant.

${ }^{7}$ Since our sample is made only of newly unemployed, the months spent in unemployment in 2006 necessarily belongs to another spell of unemployment and thus are not already included in the actual unemployment duration.
} 
The results on the role of financial condition are less clean cut. In the case of Italy mortgages, wealth and economic problems have the expected effect on unemployment duration so that individuals with less financial pressure stay unemployed longer. However, in the case of Finland this set of variables does not appear to be significant. The possible explanation of this pattern is that unemployed workers in Finland do not appear to face serious liquidity constraints so that their actual degree of wealth is not particularly relevant in the determination of unemployment duration. This interpretation is also supported from the data we described in previous section which showed that unemployed workers are equally spread in households of all wealth classes and do not appear to face particular economic problems. Finally, the results on Poland are mixed: mortgages have a positive effect on re-employment, suggesting that financial pressure have a role on duration. However, household wealth is not relevant and having major problems in making ends meet actually has a negative effect on re-employment. These latter results suggest that in a country that is facing serious economic problems and where the welfare system is not so developed, the actual pressure is not mitigated by household wealth. Two things should also be considered from this point of view. First, household wealth is relevant only in Italy, a country that is known for strict family ties so that family can act as a safety net for unemployed workers. Second, looking more in details the Polish data ${ }^{8}$ it turns out that individuals that declares to make ends meet with "some problems" have a strictly higher hazard rate than those that declared to have major problems or no problems (whose hazard rate is particularly low): this might suggests that having some problems does induce a reduction of the reservation wage and an increase in search effort, whereas having too serious problems might induce some discouragement effect.

Other, more standard, results are also found: younger and older individuals stay unemployed longer as well as individuals with lower education or living in less productive areas. Interestingly enough, gender does not have a statistically significant effect. Finally, the variable indicating that workers had been previously unemployed is clearly significant allowing us to take into account some of the unobserved heterogeneity.

In Table 3 we also reported the value of the logarithm of the logarithm ancillary parameter. Since the logarithms of these parameters are significantly greater than zero and thus, the very parameters are non-negative. Under the assumption of a Weibul distributed hazard function this implies a nondecreasing hazard function, something that supports the robustness of our results: in fact, in survival analyses, a decreasing hazard function may be a signal of self-selection into being unemployed ${ }^{9}$ and a sign that we are not including relevant variables in the regressions.

We further check the robustness of our results using the estimation from model (ii), where a semi-parametric specification was used. Almost all the results are confirmed with one important exception. The interaction of time and benefits for Finland is negative, but not significant. However the significance of this variable is quite close to the threshold level, being different from zero with $86 \%$ probability. In addition, since no systematic difference is detected between the two models, the first specification should be correct and more efficient. Given that this interaction is negative in

\footnotetext{
${ }^{8}$ In particular, in Poland, we observe that the share of individuals that found a job where: $19.9 \%$ if declaring to make ends meet "with great difficulty", $22 \%$ if declaring "with difficulty", $29.6 \%$ if declaring "with some difficulty", 27.8 if declaring "fairly easily", and 14.28 if declaring "easily" or "very easily".

${ }^{9}$ In fact declining hazard functions might be captures the desired effect of passing of time but also the permanence in unemployment of individuals whose unobserved characteristics self-select them into remaining unemploymed.
} 
both specifications, that in the second is almost significant and that first specification appears to be correct and certainly more efficient, we believe that the negative effect should be considered relevant.

We can now sum up our findings. To all extent UI have a complex effect on unemployment duration: when coordinated with employment counseling they provide incentives to the quantity and the quality of search and seem to overcome any possible negative effect due to increase of reservation wage and the reduction of search effort. However, after some time, the latter effects take over and UI seems to increase duration. This is true also in Finland, where employment services and search requirements takes place through all the duration of benefits. As for liquidity constraints they appear to be relevant in Italy and partly in Poland suggesting that they are relevant in countries where wealth and social welfare is not widespread, as seems to be the case of Finland.

\section{Conclusions}

Our analysis focused on the effect that UI schemes and liquidity constraints have on reemployment probabilities and unemployment duration and tried to tackle the different mechanism through which these aspects operates, comparing different countries. Using a sample of newly unemployed individuals from Finland, Italy and Poland in 2007, we perform an estimation of Cox hazard models. The results highlight how UI schemes may have an initial positive effect on the reemployment probabilities but, even in schemes that offer continuous employment services and expect strict and periodical search requirements, this effect revert through time. This pattern is also consistent with the results for Poland where its UI scheme, that does not provide well developed employment services, fails to increase re-employment probabilities. The role of liquidity constraints was also explored and the results we obtain are quite different depending on the country we are observing. In Italy and partly in Poland individuals with more financial pressure have shorter unemployment duration whereas in Finland these aspects are not significant. Apparently, the individuals' financial conditions are less relevant in countries where, like Finland, wealth and social welfare are widespread. Interestingly enough household wealth is only relevant for Italy, a country that is known for its strict family ties. From a policy point of view our analysis seems to suggest that unemployment benefits should be given together with employment service though strict search requirements may not be effective to promote search effort through time. Given this pattern it is advisable for benefits to be quite generous but not particularly long as, with time, they necessarily appear to increase unemployment duration. 


\section{References}

Ashenfelter, O, Ashmore, D. and Deschenes, O. 2005: Do unemployment insurance recipients actively seek work? Evidence from randomized trials in four U.S. States. Journal of Econometrics 125: 53-75.

Atkinson, A and Micklewright, J. 1991: Unemployment Compensation and Labor Market Transitions: A Critical Review. Journal of Economic Literature 29: 1679-1727.

Bloemen, H. 2002: The relation between wealth and labour market transitions: an empirical study for the Netherlands. Journal of Applied Econometrics 17: 249-268.

Card, D, Chetty, R. and Weber, A. 2007: Cash-On-Hand and Competing Models of Intertemporal Behavior: New Evidence from the Labor Market. The Quarterly Journal of Economics 122: 15111560.

Chetty, R. 2005: Why do Unemployment Benefits Raise Unemployment Durations? Moral Hazard vs. Liquidity. NBER Working Papers 11760.

Chetty R., 2008: Moral Hazard vs. Liquidity and Optimal Unemployment Insurance. Journal of Political Economy 116: 173-234.

Grambsch, P and Therneau, T. 1994: Proportional Hazards Tests and Diagnostics Based on Weighted Residuals. Biometrika 81: 515-526.

Klepinger, DH, Johnson, TR and Joesch, JM. 2002: Effects of unemployment insurance worksearch requirements: The Maryland experiment. Industrial and Labor Relations Review 56: 3-22

Manning A. 2009: You can't always get what you want: The impact of the UK Jobseeker's Allowance. Labour Economics 16: 239-250.

Nickell, S. and Layard, R. 1999: Labor market institutions and economic performance, Handbook of Labor Economics, Ashenfelter, O. and Card, D. Elsevier, volume 3: 3029-3084.

OECD. 2007. OECD Employment Outlook 2007. OECD Publishing: Paris.

OECD. 2009. OECD Employment Outlook 2009. OECD Publishing: Paris. 


\begin{tabular}{|c|c|c|c|c|c|c|}
\hline & $\begin{array}{l}\text { Ranking among } \\
\text { OECD in terms of } \\
\text { overall generosity }\end{array}$ & $\begin{array}{l}\text { Voluntary or } \\
\text { Compulsory }\end{array}$ & $\begin{array}{c}\text { Requiring } \\
\text { previous } \\
\text { employment }\end{array}$ & Amount of benefits & Max. Duration & Notes \\
\hline Finland & 9th/29 & & & & & \\
\hline $\begin{array}{l}\text { Unemployment } \\
\text { Insurance }\end{array}$ & & Voluntary & Yes & $\begin{array}{c}\text { Basic benefit of } 17 \% \text { of } \\
\text { average national wage }+45 \% \\
\text { of previous earnings } \\
\text { exceeding basic benefit }\end{array}$ & 100 weeks & \\
\hline $\begin{array}{l}\text { Unemployment } \\
\text { Assistance }\end{array}$ & & Compulsory & No & $17 \%$ of average wage & unlimited & $\begin{array}{l}\text { Amount is reduced according } \\
\text { to households income. }\end{array}$ \\
\hline Italy & 27 th/29 & & & & & \\
\hline $\begin{array}{l}\text { Unemployment } \\
\text { Insurance }\end{array}$ & & Compulsory & Yes & $\begin{array}{l}50 \% \text { of previous earnings } \\
\text { (40\% during the } 7 \text { th month) }\end{array}$ & 7 months & $\begin{array}{l}\text { Older individuals get } \\
\text { extended duration. }\end{array}$ \\
\hline Poland & 21st/29 & & & & & \\
\hline $\begin{array}{l}\text { Unemployment } \\
\text { Insurance }\end{array}$ & & Compulsory & Yes & $\begin{array}{l}24 \% \text { of the average national } \\
\text { wage, adjusted on past } \\
\text { length of employment }\end{array}$ & 6 months & $\begin{array}{l}\text { Duration is extended to } 12 \text { or } \\
18 \text { months in regions with } \\
\text { high unemployment rate. }\end{array}$ \\
\hline
\end{tabular}

\begin{tabular}{|c|c|c|c|c|}
\hline \multicolumn{5}{|c|}{ ource: OECD Employment Outlook 2009} \\
\hline Finland & $\begin{array}{l}\text { Law requires ES office to check for } \\
\text { suitable vacancies. } \\
\text { Workers' application is compulsory. }\end{array}$ & Yes & $\begin{array}{l}\text { Reports on search activity through an in- } \\
\text { person counseling interview are } \\
\text { compulsory at least once a month. }\end{array}$ & $\begin{array}{c}\text { Compulsory by law, their } \\
\text { actual frequency depends on } \\
\text { the IAP. }\end{array}$ \\
\hline Italy & $\begin{array}{l}\text { Law does not require ES office to } \\
\text { check for suitable vacancies but actual } \\
\text { efforts vary according to ES office. }\end{array}$ & Yes & $\begin{array}{l}\text { Active job search is required for workers, } \\
\text { but actual check are not required by law } \\
\text { and depends on local ES procedures. }\end{array}$ & $\begin{array}{l}\text { Not compulsory by law, but } \\
\text { they may be included in the } \\
\text { IAP. }\end{array}$ \\
\hline
\end{tabular}

Source: OECD Employment Outlook 2007 
(i)

Parametric Cox

(Weibul distribution)

Age

Age Squared

Gender

Education

Less productive region

Months of Unemployment in 2006

FINLAND

Unemployment benefits

Interaction of benefits with time

Payments for mortgage

Wealth

Problems in making ends meet

Log of ancillary parameter

ITALY

Unemployment benefits

Interaction of benefits with time

Payments for mortgage

Wealth

Problems in making ends meet

Log of ancillary parameter

POLAND

Unemployment benefits

Interaction of benefits with time

Payments for mortgage

Wealth

Problems in making ends meet

Log of ancillary parameter

$0.111 * * *$

$-0.00134 * * *$

(0.000389)

$-0.0172$

$(0.129)$

$0.309 *$

$(0.165)$

$-0.366 * *$

$(0.157)$

$-0.0413 * *$

$(0.0162)$

$0.000383 * * *$

(5.57e-05)

$-0.000527 * * *$

(0.000167)

$1.05 \mathrm{e}-05$

$(0.000129)$

0.000743

$(0.00131)$

$-0.00163$

$(0.421)$

$0.5347 * * *$

(0.081)

$0.000120 * * *$

(1.86e-05)

$-7.49 \mathrm{e}-05^{* * *}$

(2.05e-05)

8.39e-05*

(4.38e-05)

$-0.000775^{*}$

(0.000494)

$0.336^{*}$

(0.190)

$0.3797 * * *$

(0.0.45)

$-0.000130$

$(0.000872)$

$-0.00101$

(0.000494)

$0.000395^{*}$

$(0.000238)$

$-0.00630$

$(0.00634)$

$-0.406^{*}$

(0.216)

$0.4601 * * *$

(0.0685) (ii)

Semi-Parametric Cox

$0.112^{* * * *}$

(0.0285)

$-0.00136^{* * *}$

$(0.000378)$

0.0140

(0.111)

0.209

(0.139)

$-0.314 * *$

(0.136)

$-0.0461 * * *$

$(0.0143)$

$0.000251 * * *$

(6.10e-05)

$-0.000175$

$(0.000120)$

$3.18 \mathrm{e}-05$

(8.24e-05)

$-0.000214$

(0.00114)

0.0122

(0.323)

$9.08 \mathrm{e}-05^{* * *}$

(1.98e-05)

$-4.09 \mathrm{e}-05^{*}$

(2.43e-05)

$7.55 \mathrm{e}-05^{* *}$

(3.73e-05)

$-0.000689 * *$

$(0.000427)$

$0.263^{*}$

$(0.150)$

Observations

1202

$-0.00533$

(0.00478)

0.00333

(0.00299)

$0.000383 *$

$(0.000212)$

$-0.00628$

(0.00559)

$-0.356^{*}$

(0.196)

Standard errors in parentheses. Significance level: $* * * \mathrm{p}<0.01, * * \mathrm{p}<0.05, * \mathrm{p}<0.1$ 


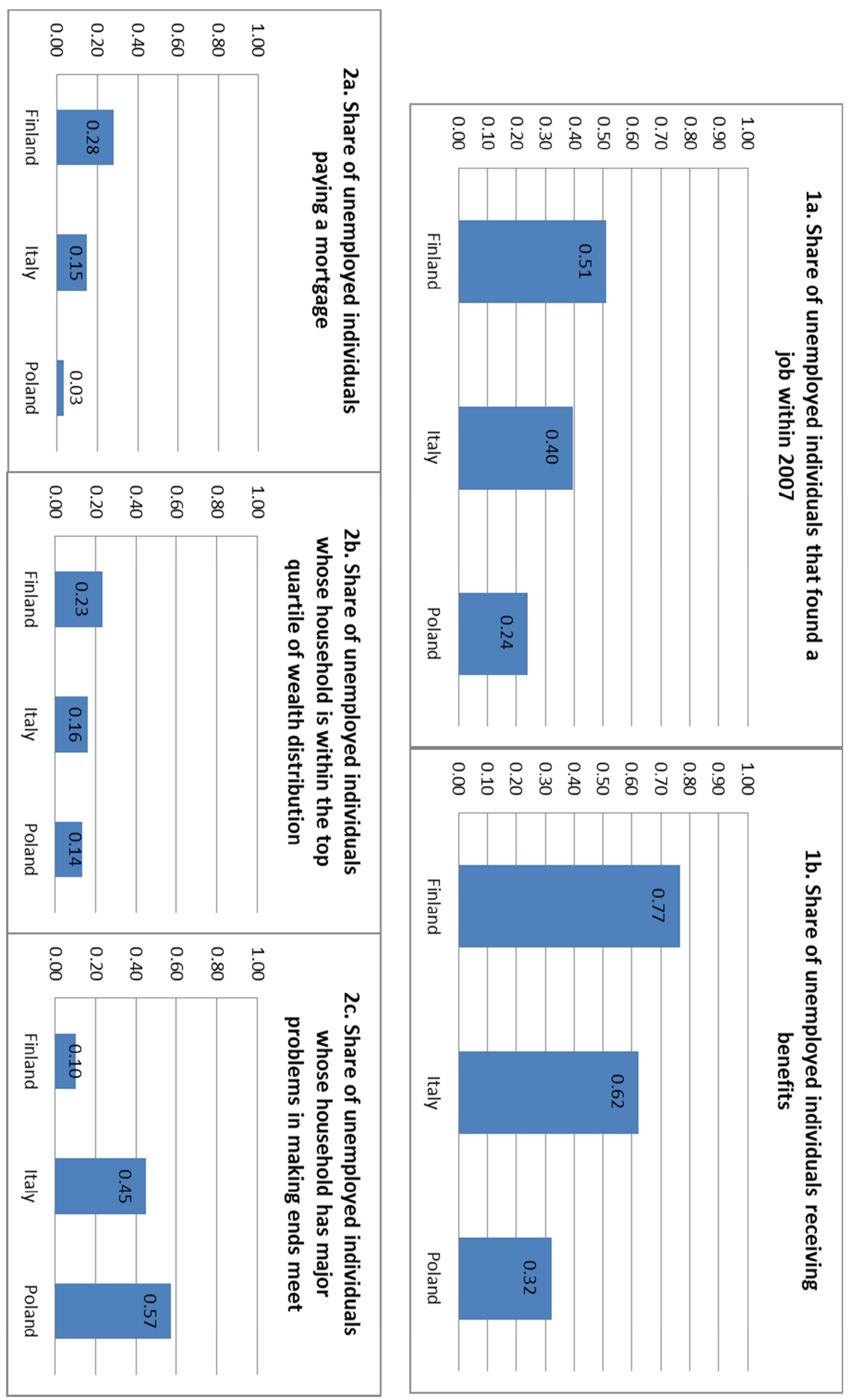


Figure 3: Hazard Estimates by Countries

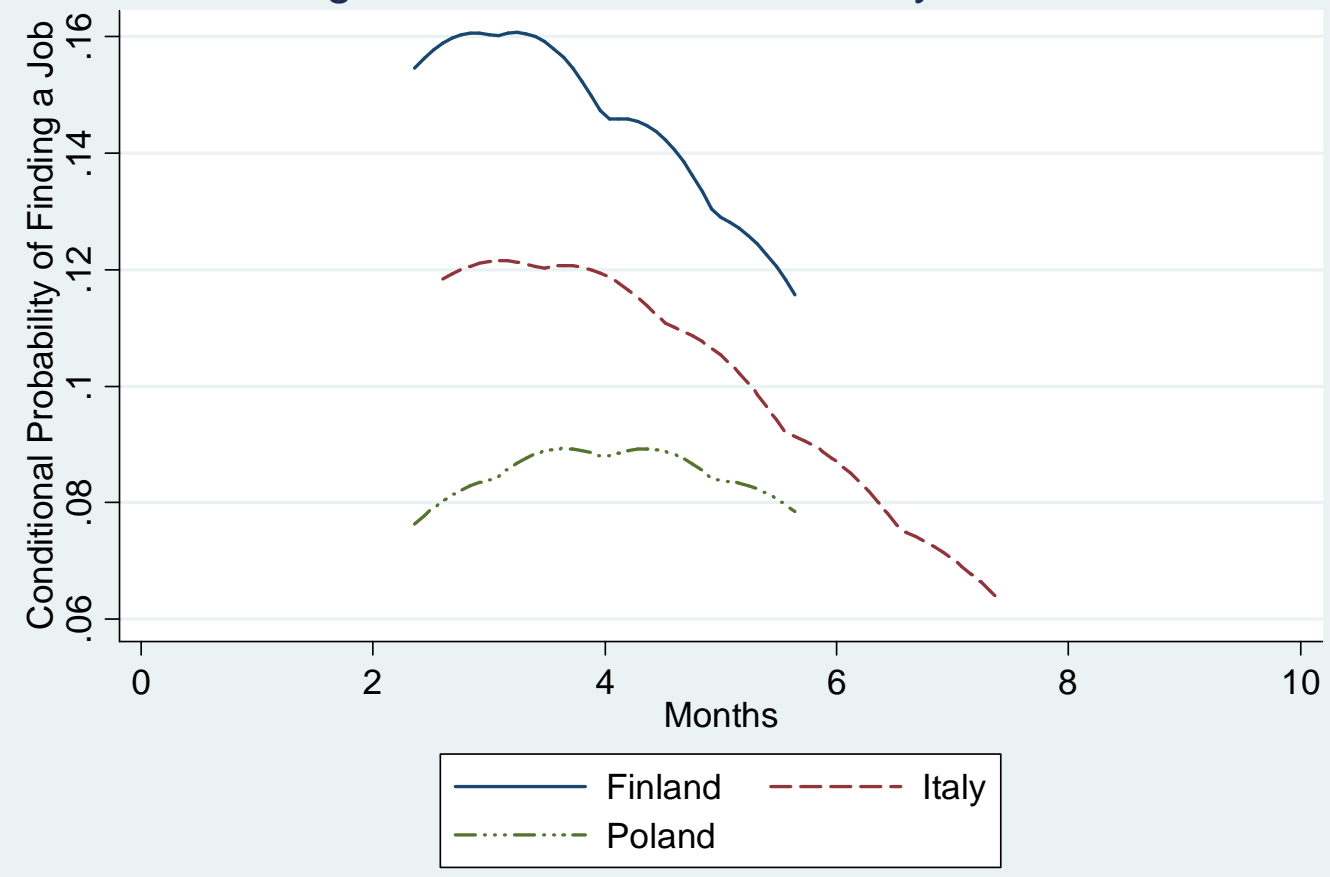

Figure 4: Hazard Rates for Individuals with and without benefits
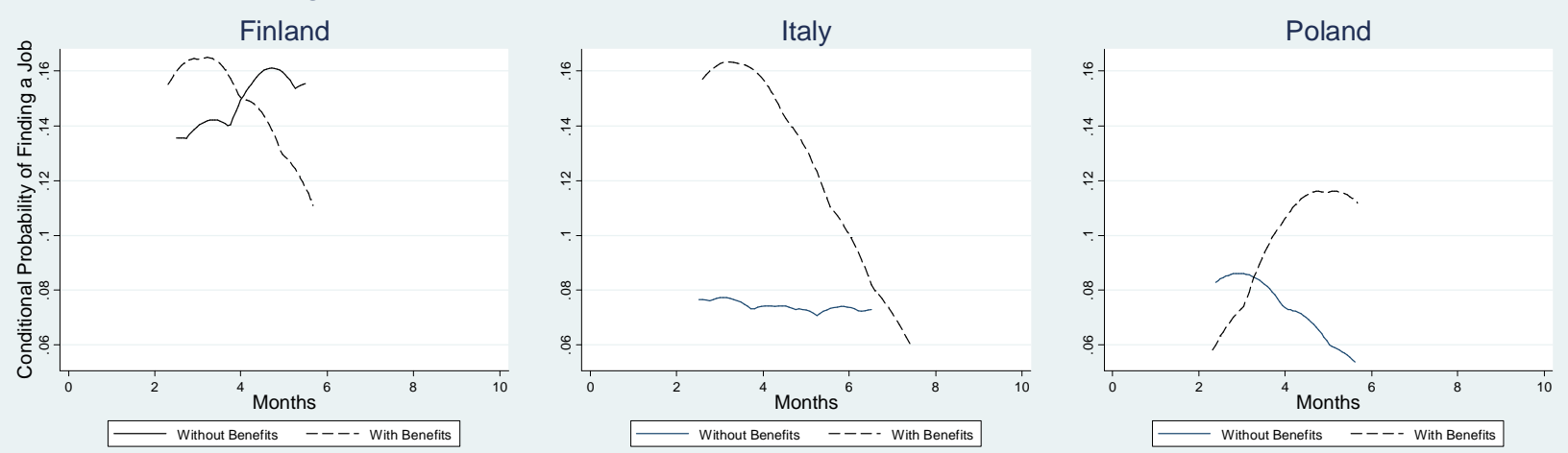